\title{
Late onset familial dystonia: could mitochondrial deficits induce a diffuse lesioning process of the whole basal ganglia system?
}

\author{
D Caparros-Lefebvre, A Destée, H Petit
}

Department of Neurology, CHU Pointe à Pitre, Guadeloupe, French West Indies, France D Caparros-Lefebvre

Departement of Neurology, CHU Lille, France

A Destée

H Petit

Correspondence to: Dr D Caparros-Lefebvre, Head of the Department of Neurology, University Hospital, route de Chauvel, F-97159 Pointe à Pitre cedex, Guadeloupe, French West Indies, France.

Received 8 November 1996 and in revised form

17 March 1997

Accepted 25 March 1997

\begin{abstract}
Background-Striatal necrosis has been related to various clinical syndromes, with acute or chronic progression, and juvenile or late occurrence, but the most common type is Leigh's encephalopathy.

Methods-Between 1967 and 1995, six out of seven related patients with chronic familial dystonia were examined. MRIs were performed in four, between 19921994. The seven members, affected over three generations, were the father, three daughters (one surviving), and three surviving grandsons.

Results-The leading symptoms were gait disorders and dystonia in all, dysarthria in six, verbal and motor stereotypies in two, and parkinsonian and cerebellar signs in three. Optic neuropathy was found in three. A frontal lobe syndrome without amnesia occurred in two. Symptoms occurred between the second and the fifth decade, with progressive deterioration. Magnetic resonance imaging, performed in four, showed in the two patients with severe neurological signs diffuse striatopallidal abnormal hyposignal (comparable with CSF signal) in T1 weighted images, suggesting extensive necrosis of the striatum and pallidum, associated with thalamo-subthalamo-rubro-dentatonigral and substantia innominata hypersignals in $\mathrm{T} 2$ weighted images suggesting gliosis in these respective areas. The same images were described to a lesser extent in a third patient. Concentrations of lactate in CSF and serum were normal in three. Muscle biopsy, performed in four, was shown to be normal. Enzyme histochemistry showed complex I, III, and IV deficiency in surviving patients.

Conclusion-This familial dystonia of chronic progression may be related to basal ganglia necrosis or gliosis, associated with alterations in the respiratory chain. These metabolic alterations probably play a part in the pathophysiology of these unusual brain lesions.
\end{abstract}

\section{(F Neurol Neurosurg Psychiatry 1997;63:196-203)}

Keywords: striatal necrosis; familial dystonia; dysarthria; mitochondrial disorders

Familial dystonia is often essential but the occurrence of striatal lucencies suggests other entities including a large group of metabolic disorders, including mitochondrial defects. ${ }^{12}$ Striatal necrosis was first described by Paterson and Carmichael, in young children. ${ }^{3}$ Later, some reports have described similar lesions in adults, ${ }^{45}$ associated with different clinical pictures. ${ }^{6}{ }^{7}$ Striatal necrosis had appeared as a common feature of subacute encephalopathy of Leigh's type. ${ }^{5}{ }^{8}$ Its relation to mitochondrial disorder has been ascertained, ${ }^{2}$ but mitochondrial diseases which represent a chemically defined entity, correspond, in fact, to an association of very different clinical syndromes, including pure encephalopathy, neuropathy, myelitis, or myopathy. ${ }^{6}$ To our knowledge, familial late onset dystonia with diffuse lesions of the basal ganglia has not previously been reported in mitochondrial diseases. Analysis of the current literature disclosed only one family of late onset dystonia with dysarthria and striatal hypodensities, reported by Druschky ${ }^{10}$; however, he did not study the respiratory chain complexes, nor the muscle biopsy. We report seven family members with dystonia. Six of these have been examined or followed up by one of us between 1967 and 1995 .

\section{Case reports}

Figure 1 gives the relation between each relative, and table 1 summarises the main clinical features.

CASE 1: PROPOSITUS I.4

His daughter (case 4) and grandson (case 5) remember that he had an abnormal gait, with probable dystonia in lower limbs. In 1914, he became divorced after his wife gave birth to a daughter (case 2). He was the father of a second daughter (case 3), before he married again. Later, he had five other children. The different family names of his children explain the delay before recognising that they were

Table 1 Summary of clinical presentation

\begin{tabular}{lllllllll}
\hline & \multicolumn{3}{l}{ Patients } \\
\cline { 2 - 7 } & 1 & 2 & 3 & 4 & 5 & 6 & 7 \\
\hline Dystonia & + & + & + & + & + & + & + \\
$\begin{array}{l}\text { Dysarthria } \\
\text { Athetoid }\end{array}$ & $\mathrm{ND}$ & + & + & + & + & + & + \\
$\quad$ movements & ND & - & + & - & - & + & + \\
Parkinsonism & ND & + & - & - & + & - & - \\
Rest hypotonia & ND & - & + & - & + & + & + \\
Cerebellar signs & ND & + & + & - & - & + & - \\
Blepharospasm & - & - & - & - & + & - & - \\
Frontal syndrome & ND & ND & ND & - & - & + & + \\
Dementia & ND & ND & + & - & - & - & - \\
\hline
\end{tabular}

$\mathrm{ND}=$ Not determined; +=positive; $-=$ negative . 


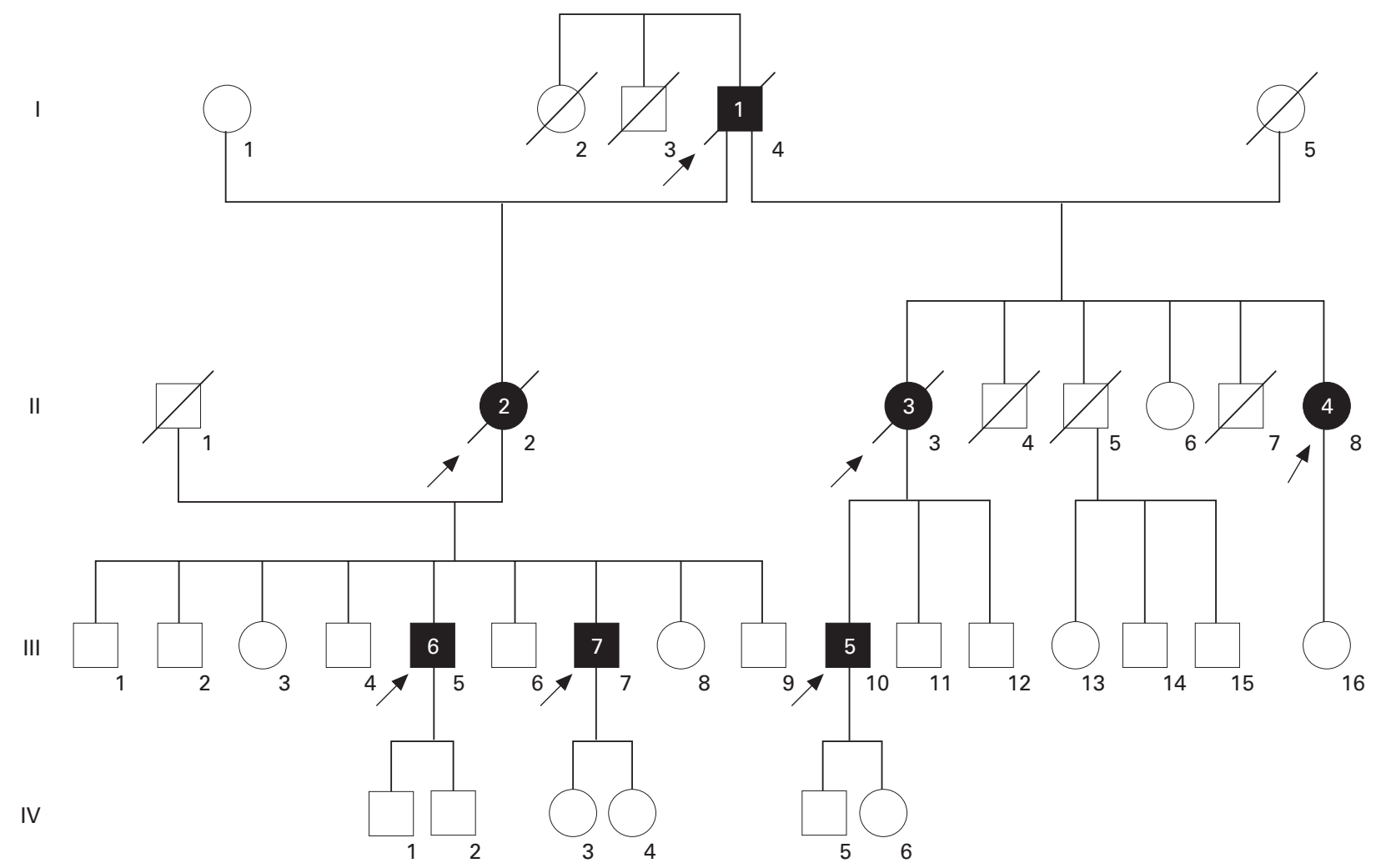

Figure 1 Family tree. $\bigcirc=$ Female; $\square=$ male; /= deceased; patients are shown in black.

relatives. He died at the age of 54, from sequelae of poison gas during the first world war, and was not necropsied. Before he died, he was able to walk only with difficulty due to dystonia and equinism.

CASE 2: PROPOSITUS II.2

This woman complained of gait disorders and dystonia at the age of 46 . No somatic disorder occurred before this period, but she had psychiatric symptoms with personality disorders. She was admitted to hospital at the age of 56. At this time, she was unable to walk, because of pronounced dystonia and cerebellar ataxia. Speech was slurred. At rest, a mild hypertonia appeared in all limbs. Rigidity was considerably increased during voluntary movement and was then associated with torsional spasms involving both legs, with equinism. Alternating movements of the hands disclosed bradykinesia. No treatment had improved the dystonia nor the rest hypertonia. The predominant features were dystonia occurring during voluntary movements, parkinsonism, and dysarthria. She died at the age of 71. A necropsy was not performed.

CASE 3: PROPOSITUS II.3

This woman had moderate gait disorders. She has been examined once in 1968. At this time, she had gait unsteadiness, with falls. Speech was explosive. No dystonic posture occurred but athetoid movements were seen in both hands. Deep tendon reflexes were brisk. She did not complain of these disorders. The axial cerebellar syndrome and abnormal movements were associated with mental deterioration. She died at the age of 67 . A necropsy was not performed.

CASE 4: PROPOSITUS II.8

She had been a nurse until the age of 58 but she had complained of gait disorders at the age of 51. She was first examined at the age of 63 , in 1992. The most striking feature was that she waddled, despite the fact that there was only mild spasticity in the legs, and mild dystonic posture in the toes of the right foot. Strength was slightly reduced proximally in both legs. No parkinsonian symptoms were present. Speech was nasal and monotonous with normal volume. Neuropsychological studies included the Wechsler memory scale, ${ }^{11}$ and parts of the Wechsler adult intelligence scale (WAIS; cubes and similitudes), ${ }^{12}$ Buschke test, ${ }^{13}$ and digit span. They showed impairment for recall of a list of words, improved by indexation (Buschke test): free recall 1: 5/16, delayed free recall: 7/16. Nerve conduction velocities (NCV), somaesthesic evoked potentials (SEP), EMG, and EEG were normal. Brain CT and MRI of the spine were normal. In 1995, MRI of the brain with T2 weighted images (1Tesla, Magnetom impact, $\mathrm{TE}=14$, $\mathrm{TR}=3200$, slice thickness $=5 \mathrm{~mm}$ ) showed diffuse abnormal hypersignal of both putamen, associated with abnormal hypersignal involving both substantia nigra. Pallidum and red nucleus density seemed to be normal. Muscle biopsy was performed when she was 62 and showed isolated ragged red fibres, corresponding to $3 \%$ of total fibres. Electron microscopy showed normal mitochondria, without inclusions. 


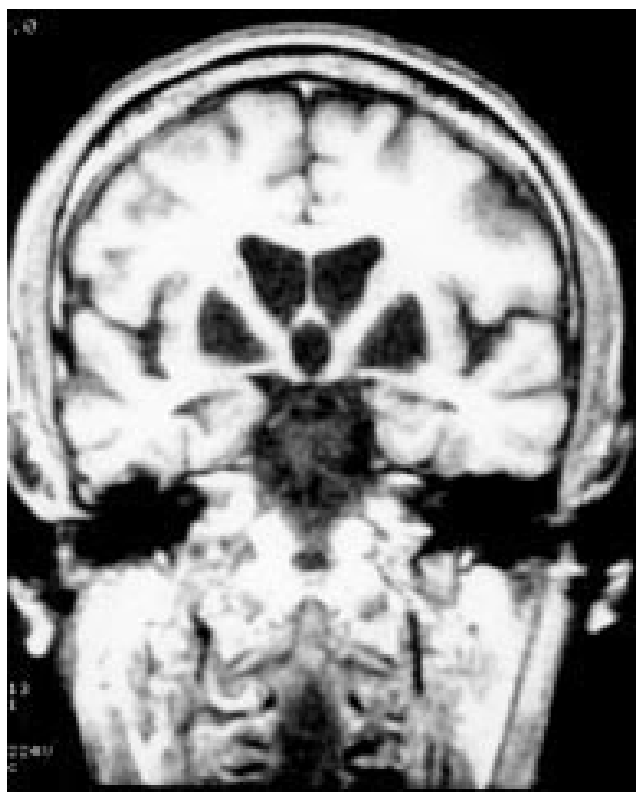

Figure 2 Case 5: MRI with T1 weighted coronal images shows diffuse abnormal putaminopallidal low intensity signal, comparable with the CSF signal.

CASE 5: PROPOSITUS III.10

This first son of case 3, born in 1935, had been a draughtsman until the age of 33 . Birth and childhood had been normal. At the age of 27 years, he noted the appearance of mild gait disorders which progressively worsened. He was admitted once in 1967, for impaired balance, dyskinesia, dysarthria with hypophonia, and swallowing impairment. At rest, hypotonia was permanent. During voluntary movements, hypertonia due to dystonia with myoclonus occurred. Dystonic movements interfered with the voluntary, precise, and rapid alternating movements of the hands, performed for bread buttering, hairdressing, drumming, or scratching. Walking was stiff, unstable, and also impaired after a few minutes by dystonic posture of the left foot. He was amimic, with monotonous speech and micrographia. There were no pyramidal signs, nor oculomotor deficit. One year later, falls occurred daily. Dystonic dysarthria worsened until speech was no longer understood in 1973. Aphonia extended to severe hypophonia in 1976. Blepharospasm occurred in 1978, and worsened progressively. It has been partly improved by repeated injections of botulin toxin, which have been continued. Other treatments orally administered (dopaminergic agonists, anticholinergic drugs) were not effective on motor disorders and were stopped. In 1995, the patient was still able to walk, with moderate dystonic posture of both feet, unstable gait, axial akinesia, taking shuffling steps, without arm swinging. He had moderate hearing loss. Neuropsychological evaluation was limited by aphonia. Verbal testing was performed using a small computer. Premorbid intelligence quotient (IQ) determined by Beauregard's automatisms ${ }^{14}$ was $36 / 40$, which corresponds to high IQ (130). Verbal memory testing from the Signoret memory battery ${ }^{15}$ was at the lower limit of normality (6/12, controls: 8.31 (SD
1.25)). Digit spans were normal ${ }^{16}$ (direct: 7 , inverse: 5). Progressive matrices of Raven (PM $47)^{17}$ were normal (A: 11 , B: 12, C: 9, time: 9 min 48 s). EEG, EMG, and NCV were normal, as was the muscle biopsy. Ophthalmological examination showed normal visual acuity and field, and a normal electroretinogram. Visual evoked potentials (VEPs) were bilaterally disorganised with decreased velocity, suggesting a mild optic neuropathy. T1 weighted coronal and axial images MRI on ( $\mathrm{TE}=12, \mathrm{TR}=$ 400) showed diffuse putaminopallidal abnormal hyposignal, comparable with CSF signal (fig 2), and to necrotic cavities, suggesting extensive necrosis of the striatum and pallidum. In T2 weighted axial images ( $\mathrm{TE}=100$, $\mathrm{TR}=2000$ ), the putaminopallidal area appeared as a large hypersignal (similar to the CSF signal). This intense abnormal signal involved the whole putamen and pallidum, and the caudate nucleus was involved to a lesser extent. A mild high intensity signal was also seen in both thalami (fig 3). At the level of the brain stem, T2 weighted axial images showed symmetric abnormal hypersignals involving the whole substantia nigra. An abnormal hypersignal was also located in both red nuclei, surrounded by a lower signal, bilaterally (fig 4 ). The coronal plane confirmed red nuclei lesions, and suggested symmetric implication of subthalamic nuclei and below of both substantia nigra (fig 5). This also showed an abnormal hypersignal surrounded by hyposignal in the cerebellum, bilaterally, in the area of dentate nuclei (fig 6). An abnormal signal was located below the pallidum and above the optic tracts in the area of the substantia innominata, probably including the Meynert's basalis nuclei, according to the atlas of Nieuwenhuys $e t \mathrm{al}^{18}$ (fig 7). This may suggest a gliosis in these respective areas : substantia nigra, thalami, red nuclei, dentate, and basalis nuclei. SPECT, using ${ }^{99 \mathrm{~m}} \mathrm{Tc}-$

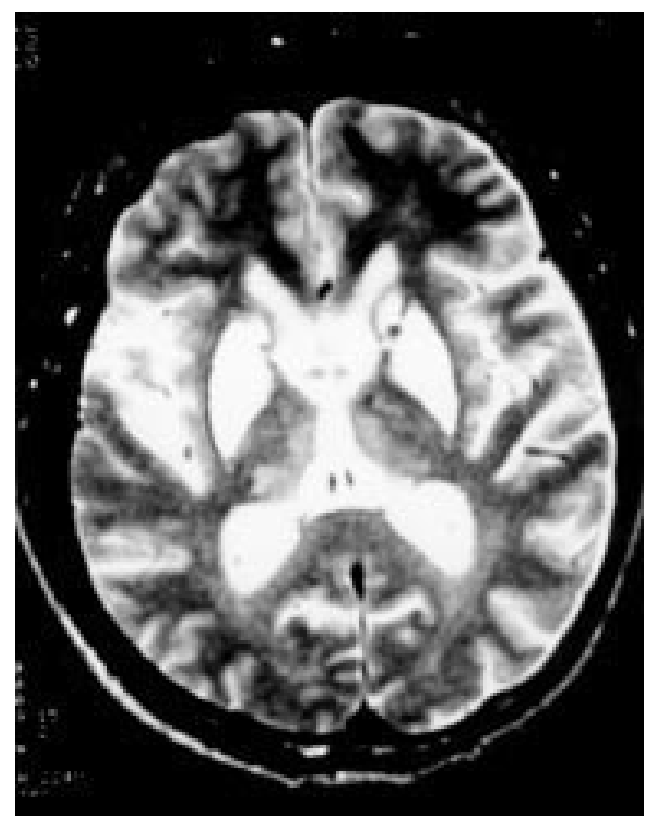

Figure 3 Case 5: in T2 weighted axial images, the putaminopallidal area appears as a large high intensity signal. The caudate nucleus is involved to a lesser extent. A mild high intensity signal also appears in both thalami. 


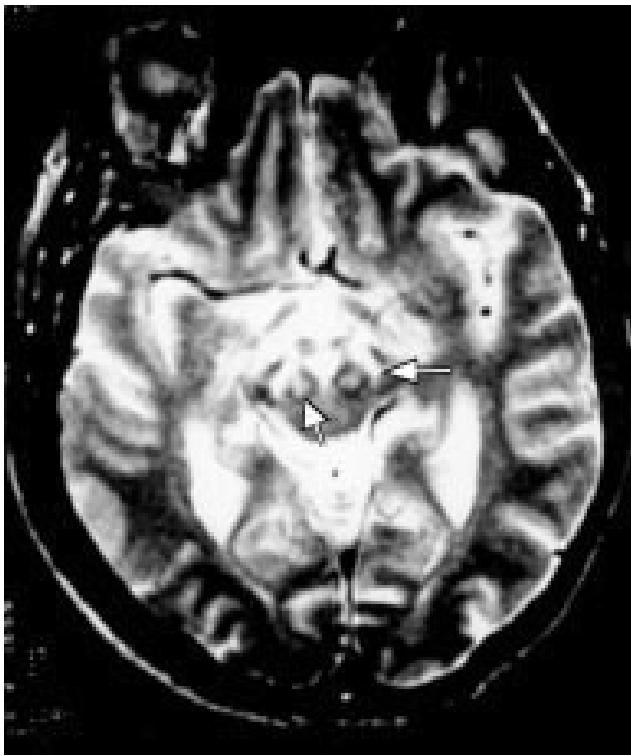

Figure 4 Case 5: T2 weighted axial images show symmetric abnormal high intensity signals involving both substantia nigra (left arrow), and both red nuclei (right arrow), which are surrounded by a lower intensity signal.

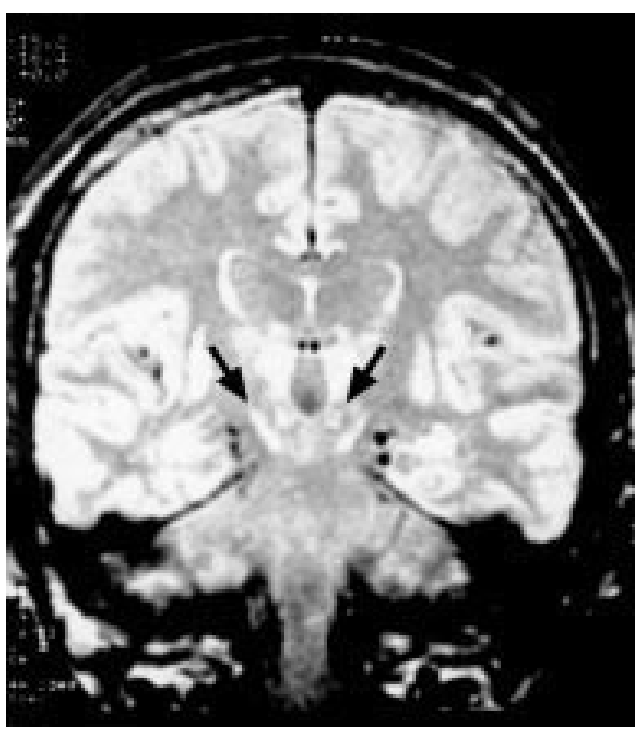

Figure 5 Case 5: the coronal plane confirms the involvement of red nuclei, medially to the subthalamic nuclei and above both substantia nigra, which were also damaged.

hexamethyl-propylene-amine-oxime $(\mathrm{Hm}-\mathrm{PaO})$ showed severe symmetric striatal hypoperfusion with bilateral prefrontal hypoperfusion.

CASE 6: PROPOSITUS III5

This third child of case 2, born in 1944, had been an engineer until the age of 32 . He complained of gait disorders at the age of 24 years. In 1970, at the age of 26, neurological examination showed dystonia. At rest, there was no abnormal posture. Walking induced progressive distorted posture of the feet, with equinism, whereas hypotonia was seen at rest. During movement or posture of the arms, athetoid movements involved the left hand. Handwriting cramps were also noted. These disorders worsened very slowly during the next five years, with gait impairment and progres-

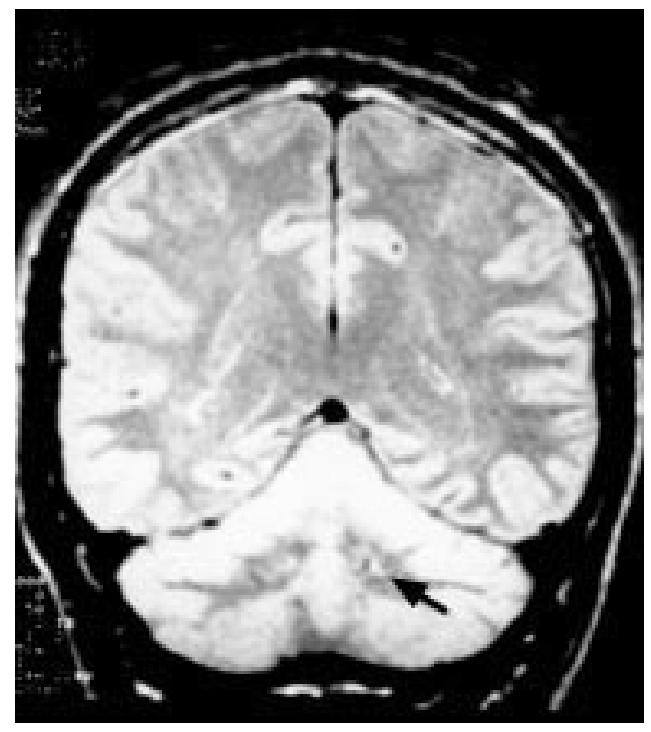

Figure 6 Case 5: posterior coronal plane shows an abnormal signal surrounded by low intensity signal in the cerebellum, bilaterally, in the area of the dentate nuclei (arrow).

sive development of cognitive disorders with a frontal lobe syndrome. In the 1980s, stereotypies developed and progressively worsened. The patient was admitted in 1994, after dystonia worsened. Dystonic postures prevented the patient from walking further than $10 \mathrm{~m}$. The frontal lobe syndrome worsened with permanent palilallia, and verbal and motor automatisms involving mainly the upper limbs. Speech was dystonic with stuttering. Writing was dystonic and macrographic. Longlasting treatment using anticholinergic drugs and dopaminergic agonists did not modify the motor status. The mini mental state examination result ${ }^{19}$ (MMSE) was 28/30. Neuropsychological study showed mild impairment in verbal and visual memory (low recall of a list of words from the Signoret memory battery: ${ }^{15} 6 / 12$, impairment of Rey figure recall: ${ }^{20} 10 / 36$ ), whereas visuoconstructional abilities were normal (Rey figure copy). Premorbid $\mathrm{IQ}^{14}$ was 125. Fluency $^{21}{ }^{22}$ was low (category: 10, letter (C): 5). The results of the Wisconsin card sorting test $^{23}$ (WCST) were abnormal: only two categories were defined, with 32 errors (including 24 perseverative errors). EEG, EMG, and $\mathrm{NCV}$ were normal, as was the muscle biopsy.

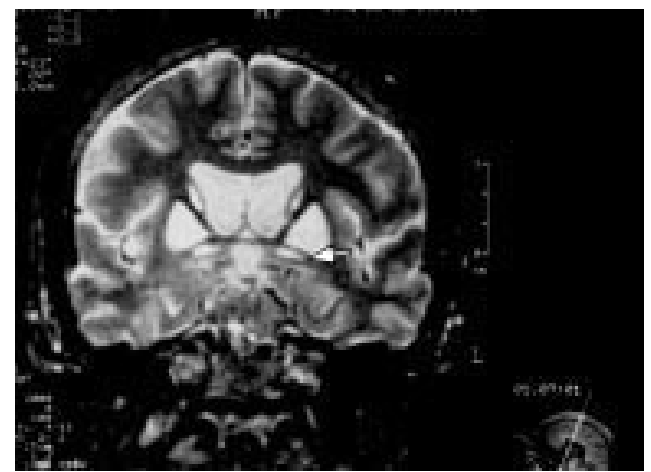

Figure 7 Case 5: an abnormal signal is located below the pallidum and above the optic tracts in the area of the substantia innominata (arrow). 


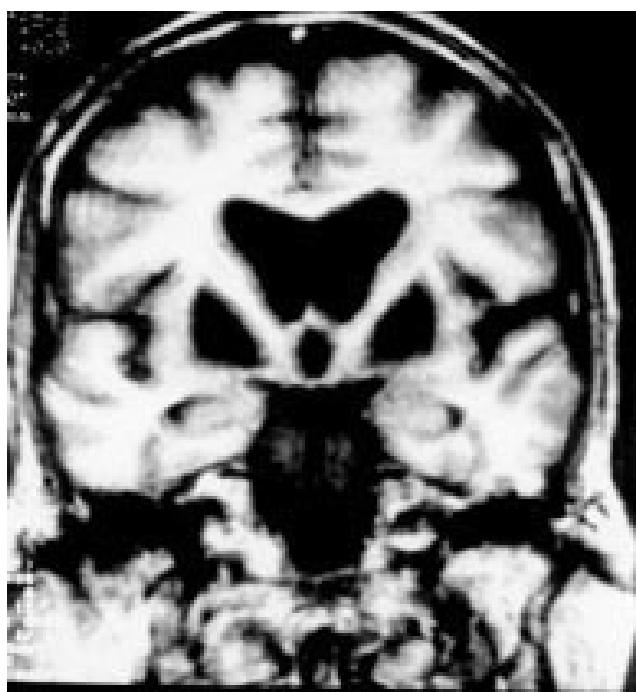

Figure 8 Case 6: T1 images show diffuse abnormal striatopallidal low intensity signal.

Visual evoked potentials were altered, with increased latency. Brain CT disclosed bilateral hypodensities involving the whole putamen and pallidum. Density analysis, using a workstation (IBM compatible computer, PIP, and SM matrox cards, original software of density analysis) showed that both striatopallidal hypodensities had the same density as the CSF in the ventricles (89 density units (DU)/ 255 DU). T1 MRI showed diffuse striatopallidal abnormal hyposignal (fig 8). In T2 images, abnormal hypersignals were seen in both substantia nigra and red nuclei, as in patient 5 . Despite sedation, the patient had moved during the MRI study. The poor quality of images did not allow assessment of other abnormalities. SPECT with $\mathrm{HmPaO}$ showed diffuse prefrontal and lenticular hypoperfusion.

CASE 7: PROPOSITUS III.7

This sixth child of case 2, born in 1949, was a highschool teacher, until the age of 45 . In 1993, he complained of writing impairment associated with abnormal movements of the right hand, dysarthria, and dysphagia. Neurological examination disclosed permanent athetoid movements of the right hand and fingers. There was right hypotonia at rest, and dystonia with hypertonia during movements. Writing was micrographic. There was left adiadocokinesia. Speech was slurred and dystonic. Constant grimacing occurred because of permanent dystonic movements of the face. Walking was slightly impaired by dystonic posture in the right foot. Symptoms worsened progressively during the next year, with the development of permanent athetoid movements in the right hand. The patient was administered levodopa with decarboxylase inhibitor (DCI), and dopaminergic agonists but no change occurred. Neuropsychological study showed normal verbal and visual memory. Fluency was low (letter: 9; category: 14). The Mattis results were low: 122/144. The patient failed to perform motor sequences, and the ability to

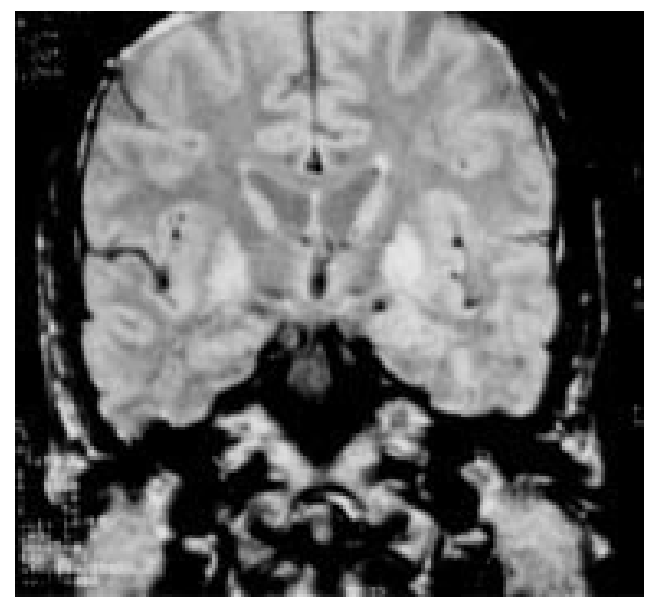

Figure 9 Case 7: one year after clinical onset, the lenticular hyperintense signals are increased in size, involving the pallidum and the putamen, although the dorsal portion of the right putamen appears less involved.

define concepts was reduced. The trail making test was impaired in time (A: $56 \mathrm{~s}, \mathrm{~B}: 185 \mathrm{~s}$ ), whereas the results of the Wisconsin card sorting test (WCST) were normal. EEG, EMG, and NCV were normal, as was the muscle biopsy. Visual evoked potentials were altered. Brain CT showed small bilateral hypodensities in both the putamen and pallidum, prevailing in the left. T2 weighted MRI of the brain showed abnormal hypersignal in the striatum, and in the right substantia nigra. After one year, hyperintensities had increased in both pallidoputaminal areas (fig 9). Bilateral abnormal hyperintensities also involved the substantia nigra and the red nuclei in which a punctiform hypersignal was seen (fig 9). SPECT showed prefrontal hypoperfusion, prevailing in the medial regions, bilaterally.

GENERAL STATUS

Of the six patients examined, none had somatic evidence of mitochondrial disorders: there was no cardiac or respiratory failure, no auditory or

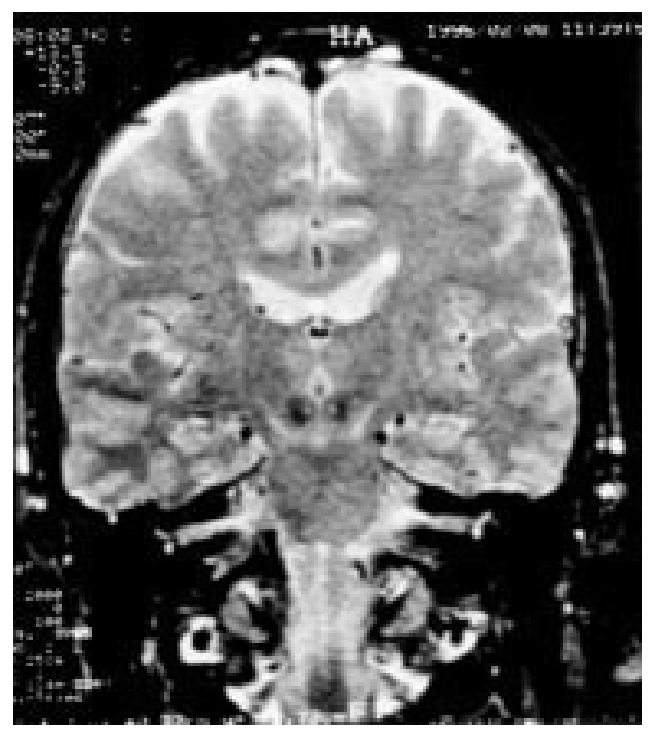

Figure 10 Case 7: nigral high intensity signals are bilateral, associated with a punctiform high intensity signal in the red nuclei. 
Table 2 Studies of respiratory chain compounds and mitochondrial DNA

\begin{tabular}{|c|c|c|c|c|c|}
\hline Complex & $\begin{array}{l}\text { Controls }(n=29) \\
(\text { mean }(S D))\end{array}$ & $\begin{array}{l}\text { Patient II-8 } \\
\text { (case 4) }\end{array}$ & $\begin{array}{l}\text { Patient III-5 } \\
\text { (case 6) }\end{array}$ & $\begin{array}{l}\text { Patient III-7 } \\
\text { (case 7) }\end{array}$ & $\begin{array}{l}\text { Patient III-10 } \\
\text { (case 5) }\end{array}$ \\
\hline Total I & (14) & 13 & 19 & 16 & 12 \\
\hline I (with rotenone) & (13) & 7 & 5 & 10 & - \\
\hline II + III & $(7)$ & 18 & 16 & 15 & - \\
\hline III antim & (33) & 71 & 57 & 57 & 87 \\
\hline IV & (24) & 54 & 39 & 57 & 85 \\
\hline Citrate synthetase (CS) & (71) & 105 & 196 & 144 & 97 \\
\hline III / CS & $1.08(0.61)$ & 0.53 & 0.32 & 0.40 & 0.90 \\
\hline IV / CS & $0.68(0.46)$ & 0.51 & 0.22 & 0.40 & 0.90 \\
\hline I / CS & $0.21(0.13)$ & 0.07 & 0.03 & 0.07 & - \\
\hline IV / II+III & $3.35(1.36)$ & 3.60 & 2.44 & 3.17 & - \\
\hline III / II+III & $6.34(2.56)$ & 3.94 & 3.56 & 3.17 & - \\
\hline Mitochondrial DNA & - & Normal & Normal & Normal & Normal \\
\hline
\end{tabular}

Values in bold were below the lowest control value. Rotenone = rotenone dependent activity; antim = antimycine dependent activity; - = not measured.

muscular involvement, and no ophthalmoplegia, and no hepatic or renal failure. None of the patients had a history of toxic misuse, or poisoning by methanol, thiocyanate, or 3-nitropropionic acid. Clinical and biological studies failed to show symptoms suggesting Wilson's disease.

In all alive patients, CSF and blood studies were normal. Lactate concentration was normal in serum and CSF at rest, but increased abnormally in two patients (6 and 7) during and after physical exercise. In the other patients, physical exercise could not be performed. The methodology of muscle biopsy and respiratory chain compound study has been described previously. ${ }^{24}$ The assays were performed on frozen muscle samples kept in dry ice or at $-80^{\circ} \mathrm{C}$, obtained by a surgical technique from deltoid muscle. Parts of the muscle biopsies were serially sectioned and then subjected to a histochemical staining battery including the modified Gomori trichrome technique, Cytochrome oxydase (COX), nicotinamide adenine dinucleotide-tetrazolium reductase (NADH-TR), succinate dehydrogenase $(\mathrm{SDH})$, and myosin-adenosine triphosphate (ATPase). The percentage of ragged red fibres or COX negative fibres recorded for each patient was below 3\% except in the oldest patient. Electron microscopy was normal in all studied cases. Respiratory chain compounds were detected by spectrophotometry. The analysis included NADH ubiquinone oxidoreductase (complex I) measurement with and without rotenone in parallel cuvettes, succinate cytochrome c oxidoreductase (complexes II + III), ubiquinol cytochrome c oxidoreductase (complex III) measured with and without antimycin A in parallel cuvettes, cytochrome c oxidase (complex IV), and citrate synthetase (DTNB as acceptor). With the parallel cuvettes, the technical conditions of analysis are identical. The results were compared with those of 29 normal controls (table 2). The total DNA was extracted from small parts of frozen muscle, digested by a restriction enzyme, run on agarose gel, and transferred to nitrocellulose. Mitochondrial DNA of muscle was analysed by Southern blot using two probes at the same time: total mitochondrial DNA extracted from human placenta and CDNA probe of the human $28 \mathrm{~S}$ gene. In all cases, total complex I was reduced. After the rotenone step, the complex I was below the lower value of controls in all cases, significantly reduced in cases 4 and 6 . The complexes II, III, and citrate synthetase results were not available in patient III.10 because of impaired conservation. Complex I and complex III were decreased in the other three patients, in comparison with controls. Complex IV was decreased in two. Complexes II + III were normal. Mitochondrial DNA study was normal in all cases, failing to show any deletion or known mutation.

\section{Discussion}

We have isolated a new clinical syndrome of familial dystonia. Clinical and radiological features suggest a new entity which differs from previous descriptions of mitochondrial diseases. ${ }^{25-28}$ Despite an apparent clinical heterogeneity, all of our patients were affected by dystonia and dysarthria. The dysarthria was assessed in six patients. The prominent feature was the dystonia occurring only during movements, and disappearing completely at rest. The same biochemical disorder, and probably the same brain lesions, had induced strikingly different clinical patterns, with various degrees of cerebellar and parkinsonian syndromes. Of the two most disabled patients displaying the same MR images, parkinsonian signs were predominant in one, while dystonic and cerebellar signs were predominant in the other. Athetoid movements occurred in cases 3 and 7 , who were not directly related, whereas dystonia was prominent in the others. Frontal lobe syndrome occurred in three patients, whereas none of these patients had all of the specific criteria for the diagnosis of dementia. A severe behavioural impairment of the frontal lobe type was seen in only one of the surviving patients (case 6). The most impressive feature was his permanent motor and verbal automatisms. In case 7 , the brother of case 6 , the frontal lobe syndrome involved only instrumental skills. The most affected test was the motor sequences, whereas other tests (including WCST) were normal. Graphic sequences were normal. The specific impairment of motor sequences may reflect a subtle frontal lobe syndrome. Nevertheless, these dissociated results could also be explained by a different sensitivity of frontal lobe tasks. The syndromic association of action dystonia, with frontal lobe symptoms or athetoid movements, without dementia is uncommon in the current litera- 
ture. We have shown evidence that this syndrome is related to a mitochondrial cytopathy because all of our patients had a complex I defect which appeared either alone, or associated with complex III or IV defect. These partial defects of complexes I, III and IV were associated with a unique pattern of deep brain lesions involving only the basal ganglia, which may be compared only to Leigh's disease and related rare mitochondrial disorders.

The long-lasting course of the disease could have suggested degenerative process such as luysopallidonigral atrophy, which is a familial inherited disease, disclosed by rigidity, parkinsonism, and cognitive impairment. ${ }^{29}$ Other related syndromes, with involvement of the pyramidal tract, thalami, or dentate nuclei, have been described, ${ }^{30-32}$ but none of them displayed putaminal lesions, nor spongiosis (or necrosis) of the lenticular formation. The clinical syndrome that we have described is different from previously described mitochondrial encephalopathy which usually induces multivisceral failure. Common phenotypical syndromes involving the CNS: Leber's disease, ophthalmoplegia plus syndromes, and Leigh's disease, could be compared with our cases, as they displayed either parkinsonian syndrome or striatal lesions. However, many extrapyramidal syndromes associated with mitochondrial disorders have not been clearly classified, because of their polymorphism. ${ }^{6}$ The long-lasting predominance of movement disorders is unusual in mitochondrial diseases. ${ }^{67}$ Different symptoms of mitochondrial encephalomyopathy were missing in our patients. There was no peripheral neuropathy, either clinically or electrophysiologically. There were no seizures, nor ophthalmoplegia. Previous anatomical, CT, or MRI case reports of lenticular lesions have been reported and may be compared with our cases. Leigh's disease, a heterogenous entity defined by subacute necrotising encephalomyelopathy occurring in children, has also been reported in adults, with chronic evolution. ${ }^{45} \mathrm{It}$ is usually sporadic, but autosomal dominant forms have been reported. ${ }^{33}$ This condition differs from our patients as the pallidum is inconsistently involved, the red nuclei is spared, and the periaqueductal grey matter is usually destroyed. ${ }^{5}$ In Leber's disease, which is transmitted by females, optic atrophy is prominent, but dystonia has been reported by many authors, associated with putaminal lucencies. ${ }^{34-36}$ However, an overlap between these diseases is probable. ${ }^{37}$ Anatomical study in Leigh's disease, reported by Garcin et al, obviously showed involvement of Meynert's basalis nucleus, as in our patients. ${ }^{38}$ The family described by Druschky ${ }^{10}$ had the same clinical features as ours: long-lasting dystonia, with dysarthria and autosomal dominant transmission, but both MRI and anatomical study confirmed that the pallidum was not involved. In our two most disabled patients, MRI showed lenticular and caudate hyposignals, suggesting necrotic cavities or spongiosis. In case 7, MRI follow up showed that the pathological process started probably in the pallidum, the ventral part of the putamen and the substantia nigra, and was asymmetric. The muscle biopsies seemed to be normal morphologically but disclosed biochemistry abnormalities, and were then useful. The mode of inheritance seems to be autosomal dominant, whereas most mitochondrial diseases associated with mitochondrial DNA mutation or deletion are usually sporadic ot transmitted by women. In our family, the transmission suggested nuclear, rather than mitochondrial DNA alterations.

The pathogenic role of these metabolic defects in the development of the brain lesions remains to be proved. The implication of mitochondrial dysfunction in the pathogenesis of movement disorders has been demonstrated in several ways: (1) mitochondrial DNA mutations have been found in both unusual syndromes associating chorea and dementia, ${ }^{39}$ and subacute or chronic forms of striatal necrosis $;^{40}$ (2) the dosage of respiratory chain complexes shows a specific decrease in complex I in the substantia nigra of parkinsonian patients, ${ }^{41}{ }^{42}$ in multiple system atrophy, and sporadic or familial cases of late onset cerebellar degeneration. ${ }^{62}$ This suggests that the basal ganglia system is extremely sensitive to complex I defect. Different pathogenic factors have been discussed for the explanation of tissue lesions in mitochondrial disorders: infarction in anoxic tissue with secondary microangiopathy or primary involvement of small arteries. It has also been shown that mitochondrial toxins produce striatal excitotoxic lesions, by a mechanism involving energy depletion in vivo. ${ }^{43}$ The delayed occurrence of symptoms with chronic progression in our patients could be due to both partial defects in the mitochondrial respiratory chain, and the effect of aging. We did not show mitochondrial DNA mutation or deletion, which is not surprising in an autosomal dominant transmission. Different mutations have been found in Leigh's syndrome, and other primary dystonias. ${ }^{40}$ However, degenerative dystonia never displayed necrotic lesions involving the lenticular formation. Mitochondrial defects might be linked to toxins such as 1-methyl-4-phenyl-1,2,3,6-tetrahydropyridine, and medications such as neuroleptic drugs. ${ }^{44}$ These causal factors could not explain the occurrence of the striatal necrosis of our patients, nor the clinical features, particularly the cerebellar signs.

In conclusion, we think that we have recognised a new clinical entity of hereditary mitochondrial striatopallidonigral disease which is expressed as a late onset progressive dystonia and finally involves the entire basal ganglia. The genetic defect underlying this disease still remains to be determined.

We are grateful to Dr A Lombes for the biological and mitochondrial study. We thank Dr AL Benabid for valuable comments and suggestions. We also thank Drs JP Pruvo and MM Ruchoux for their contribution to the radiological and pathological studies, and Dr E Boogusch for proof reading the manuscript.

1 Calne DB, Lang AE. Secondary dystonia. In: Fahn S, et al, eds. Advances in neurology. Vol 2. New York: Raven Press, 1986:9-33.

2 DiMauro S, Bonilla E, Zeviani M, Nakagawa M, DeVivo DC. Mitochondrial myopathies. Ann Neurol 1985;17:521- 
3 Paterson D, Carmichael EA. A form of familial cerebral degeneration chiefly affecting the lenticular nucleus. Brain degeneration chie $1924 ; 47 ; 207-31$.

4 Berkovic SF, Karpati G, Carpenter S, Lang AE. Progressive dystonia with bilateral putaminal hypodensities. Arch Neurol 1987;44:1184-7.

5 Kissel JT, Kolkin S, Chakeres D, Boesel C, Weiss K. Magnetic resonance imaging in a case of autopsy proven
adult subacute necrotizing encephalomyelopathy (Leigh's disease). Arch Neurol 1987;44:563-6.

6 Truong DD, Harding AE, Scaravilli F, Smith SJM, MorganHughes JA, Marsden CD. Movement disorders in mitochondrial myopathies. A study of nine cases with two autopsy studies. Mov Dis 1990;5:109-17.

7 D'Alessandro R, Tinuper P, Lozito A, Sacquegna T, Cortelli P, Pazzaglia P. CT scan in a case of progressive generalized dystonia with amyotrophic paraplegia. Ital $7 \mathrm{Neurol} \mathrm{Sci}$ 1983;3:335-7.

8 Marsden CD, Lang AE, Quinn NP, McDonald WI, Abdallat A, Nimri S. Familial dystonia and visual failure with lat A, Nimri S. Familial dystonia and visual failure with 1986;49:500-9.

9 Estournet B, Duyckaerts C, Marsac C, Chabri N, Bataille J, ondriale familiale. Etude clinico-pathologique. Rev Neurol 1991;147:491-6.

10 Druschky KF. Hereditary putaminal necrosis. In: Vinken PJ, Bruyn GW, Klawans HL, eds. Handbook of clinical neurology. Vol 49. Amsterdam, Elsevier Science, 1986: 493-8.

11 Wechsler D. Echelle Clinique de Mémoire. Paris, France: Centre de psychologie appliquée, 1969.

12 Wechsler D. WAIS-R manual. New York: Psychological Corporation, 1981

13 Buschke H, Fuld PA. Evaluating storage retention, and retrieval in disordered memory and learning. Neurology 1974;24:1019-25.

14 Beauregard A. Le test des automatismes verbaux. Issy-lesMoulineaux: Editions scientifiques et psychotechniques. 1971.

15 Signoret JL, Whiteley A. Memory battery scale. International Neuropsychological Society Bulletin 1979;2:26.

16 Miller GA. The magical number seven, plus or minus two: some limits on our capacity for processing information. Psychol Rev 1956;63:81-97.

17 Raven J. Manuel des matrices progressives. Issy-lesMoulineaux: Editions scientifiques et psychotechniques, 1981.

18 Nieuwenhuys R, Voogd J, Van Huijzen C. The human central nervous system. 3rd ed. Berlin: Springer Verlag, 1988

19 Folstein MF, Folstein SE, Mac Hugh PR. "Mini-mentalstate", a practical method for grading the cognitive state of patients for the clinician. F Psychiatr Res 1975;12:189-98.

20 Rey A. L'examen psychologique dans les cas d'encéphalopathie traumatique. Arch Psychol 1941;28:286340.

21 Benton AL. Differential behavioral effects in frontal lobe disease. Neuropsychologia 1968;6:53-60.

22 Cardebat D. Evocation lexicale formelle et sémantique chez les sujets normaux. Acta Neurol Belg 1990, 90:207-17.

23 Nelson HE. A modified card sorting test sensitive to frontal lobe defects. Cortex 1976;12:313-24.

24 Lombes A, Bonilla E, Di Mauro S. Encéphalopathies mitochondriales. Rev Neurol 1989;145:671-89.

25 Fukuhara N, Tokiguchi S, Shirakawa K, Tsubaki T. Myoclonus epilepsy associated with ragged-red fiber (mitochondrial abnormalities): disease entity or a syndrome ? F Neurol Sci 1980;47:117-33.
26 Nikoskelainen EK, Marttila RJ, Juvonen V, Lamminen T, Sonninen P, Savontaus ML. Leber's "plus": neurological patients with Leber's hereditary optic neuropathy. F Neurol Neurosurg Psychiatry 1995;59:160-4.

27 Donnet A, Guinot H, Pelissier JF, Desnuelle C, Cozzone P, Bouchacourt M, Khalil R. Dystonie segmentaire et encéphalomyopathie mitochondriale. Rev Neurol 1992;148: $51-3$.

28 Davous $\mathrm{P}$, Khoubesserian P, Tric P, Telerman-Toppet N. Encéphalopathie mitochondriale avec atteinte exclusive du système nerveux central. Rev Neurol 1991;147:538-41.

29 Van Bogaert L. Aspects cliniques et pathologiques des atrophies pallidales et pallido-luysiennes progressives. $\mathcal{F}$ Neurol Neurosurg Psychiatry 1940;9:125-57.

30 Gray F, Eizenbaum JF, Gherardi R, Degos JD, Poirier J. Luyso-pallido-nigral atrophy and amyotrophic lateral sclerosis. Acta Neuropathol (Berl) 1985;66:78-82.

31 Neumann MA. Combined degeneration of globus pallidus and dentate nucleus and their projections. Neurology 1959; 9:430-8.

32 Kosaka K, Oyanagi S, Matsushita M, Hori A, Iwase S. Multiple system degeneration involving thalamus, reticular formation, pallido-nigral, pallido-luysian and dentato-rubral systems. Acta Neuropath 1977;39:89-95.

33 Miyoshi K, Matsuoka T, Mizushima S. Familial holotopistic striatal necrosis. Acta Neuropathol (Berl) 1969;13:240-9.

34 Bruyn GW, Vielvoye GJ, Went LN. Hereditary spastic dystonia: a new mitochondrial encephalopathy? $f$ Neurol Sci 1991;103:195-202.

35 Rondot P, de Recondo J, Davous P, Fredy D, Roux FX. Rigidité extrapyramidale avec dystonie, atrophie optique et atteinte bilatérale du putamen chez un adolescent. Rev neurol 1982;138:143-8.

36 Novotny EJ, Singh G, Wallace DC, Dorfman LJ, Louis A, Sogg RL, Steinman L. Leber's disease and dystonia: a mitochondrial disease. Neurology 1986;36:1053-60.

37 Leuzzi V, Bertini E, de Negri AM, Galluci M, Garavaglia B. Bilateral striatal necrosis, dystonia and optic atrophy in two siblings. F Neurol Neurosurg Psychiatry 1992;55:16-9.

38 Garcin R, Gruner J, Godlewski S. Spongiose disséminée de l'encéphale évoluant cliniquement par poussées chez un enfant malgache. Rev Neurol 1956;95:273-83.

39 Nelson I, Hanna MG, Alsanjari N, Scaravilli F, MorganHughes JA, Harding AE. A new mitochondrial DNA mutation associated with progressive dementia and chorea: a clinical, pathological, and molecular genetic study. Ann Neurol 1995;37:400-3.

40 Thyagarajan D, Shanske S, Vazquez-Memije M, DeVivo D, DiMauro S. A novel mitochondrial ATPase 6 point mutation in familial bilateral striatal necrosis. Ann Neurol 1995; 38:468-72.

41 Schapira AHV, Mann VM, Cooper JM, Dexter D, Daniel $\mathrm{SE}$, Jenner $\mathrm{P}$, et al. Anatomic and disease specificity of NADH CoQ1 reductase (complex I) deficiency in Parkinson's disease. f Neurochem 1990;55:2142-5.

42 Schulz JB, Beal MF. Mitochondrial dysfunction in movement disorders. Curr Opin Neurol 1994;7:333-9.

43 Flint Beal M, Ross Henshaw D, Jenkins BG, Rosen BR, Schulz JB. Coenzyme $\mathrm{Q}_{10}$ and nicotinamide block striatal lesions produced by the mitochondrial toxin malonate. Ann Neurol 1994;36:882-8.

44 Shoffner JM. Mitochondrial defects in basal ganglia diseases. Curr Opin Neurol 1995;8:474-9. 